\title{
Evolutionity and the Calling of Evolutionary Suffering and Evolutionary Flourishing: Dialogues Among Epochs and Cultivating New Pathways of Planetary Realizations
}

\author{
Ananta Kumar Giri \\ Madras Institute of Development Studies, Chennai, India \\ Email address: \\ aumkrishna@gmail.com, ananta@mids.ac.in \\ To cite this article: \\ Ananta Kumar Giri. Evolutionity and the Calling of Evolutionary Suffering and Evolutionary Flourishing: Dialogues Among Epochs and \\ Cultivating New Pathways of Planetary Realizations. International Journal of Philosophy. Special Issue: Evolutionity. \\ Vol. 9, No. 3, 2021, pp. 154-161. doi: 10.11648/j.ijp.20210903.16
}

Received: April 28, 2021; Accepted: June 18, 2021; Published: August 24, 2021

\begin{abstract}
Evolution is a perennial challenge before Nature, self, society and the world. This article engages with the discourse of evolutionity offered by W. Julian Korab-Karpowicz to characterize our contemporary condition. Korab-Karpowicz argues that our contemporary condition is not so much characterized by tradition, modernity and postmodernity but evoultionity which refers to processes of evolution on the part of self and society. This article engages with this perspective and argues how evoultionity is characterized by evolutionary suffering which then leads to evolutionary flourishing. Evolutionary suffering refers to pain and suffering undertaken for realizing evolutionary transformations of self, society and the world. Evolutionary flourishing refers to realization of beauty, dignity and dialogues in self and society as evolutionary process. The article also argues how the present moment is not only characterized by clash among epochs but by dialogue among epochs. The theme of clash of epochs which draws on the discourse of clash of civilizations needs to engage with discourses and practices of dialogues among civilizaitons. Here the article offers the perspectives of multi-topial and multi-temporal hermeneutics to understand dialogues among epochs. In multi-topial hermeneutics one moves across multiple terrains of self, society, culture and the world and in multi-temporal hermeneutics one moves across multiple temporality. The article thus argues how dialogues among epochs need to be understood in the context of dialogues among cultures, civilizations and temporality. The article argues how in our contemporary moment we need to realize that we all are children of Mother Earth which is called planetary realizations in this essay.
\end{abstract}

Keywords: Evolutionary Flourishing, Evolutionary Suffering, Dialogues Among Epochs, Multi-topial Hermeneutics, Multi-temporal Hermeneutics, Transmodernity, Lokasamgraha, Tian-Xia

\section{Opening Epigraphs}

We are vehicles of further evolution. In this phase evolution is no longer related merely to matter, but proceeds through the development of mind, as it is expressed in our scientific and technological achievements. However, the expansion of knowledge aimed at our intellectual perfection is not enough, if ethics is lacking. [..].

We were not born here on Earth to become consumers or militants" (7.76), nor to merely to seek wealth and power, but to fully develop morally and intellectually. Power, ability to do something, can only be a means, never the goal, which is our perfectibility. Within the universe as we know it, we represent the pinnacle of evolution. This is reflected in our ability to think, invent things, and plan ahead, and in our capacity for ethical thought. However, we are not yet complete beings. At present, there is a huge difference between the development of our scientific knowledge and techno-logical abilities, and our moral growth. Morality and rationality are dynamic phenomena; they cannot be prescribed by unchanging rules, but have to be internalized. We can still further develop in ourselves our moral sensitivity and intellectual curiosity. We may include in the basic imperative "do not harm" not only our fellow human beings, but also the animal world and even the natural world at large. We can enlarge our understanding of the place and role of 
human beings in the universe and our ecological awareness. At this stage, human evolution becomes a conscious evolution, a self-transforming process [1].

The classical dichotomies between internal and external, organism and environment, face radical questions. Why must we think that one of the two polarities plays an active role (as cause), and the other plays a passive role (as environment (which poses the question), and the organisms are nothing but objects this force plays upon? [..] Living systems are not collections of traits or characteristics that are passively subject to direction imposed on them by various environmental forces. They are autonomous and active entities that themselves contribute to the creation and modulation of these forces. Evolution is always a coevolution [2].

In human life, Suffering is the antitheses of Power, and it is also a more characteristic, and more fundamental element in Life than Power is. [..] Suffering is the essence of Life, because it is the inevitable product of an unresolvable tension between a living creature's essential impulse to try to make itself into the center of the Universe and its essential dependence on the rest of creation and on the Absolute Reality on which all creatures live and move and have their being. On the other hand, human power, in all its forms is limited and, in the last resort, illusory. Therefore, any attitude towards Life that idolizes human power is bound to be a wrong attitude towards Suffering and, in consequence, a wrong attitude towards Life itself [3].

\section{Introduction and Invitation}

In his Tractatus Politico-Philosophicus and in his more recent works, W. Julian Korab-Karpowicz has been inviting us to look at and realize our contemporary moment with the vision and practice of evolutionity where we strive for evolutionary development of self, society and humankind. He presents this as an aspect of our future condition-social as well as self-where we are animated by an urge to evolve building upon our participation as well as overcoming the limitations of conditions related to tradition, modernity and postmodernity. Presenting the upcoming evolutionary epoch as an epoch of evolutionity, Korab-Karpowicz tells us:

It is the evolutionary epoch that replaces modernity and postmodernity. While modernity was inspired by the mechanistic, materialistic, and deterministic view of the universe emerging from Newtonian physics and tried to apply this view to living organisms and social phenomena, and postmodernity has been characterized by unsolved problems related to globalization, political instability, and a regress to irrationality, the evolutionary epoch or evolutionity is inspired by the idea of human evolution, and by the organic and holistic worldview emerging from the new science. It is not revolutionary, like most modern and post-modern intellectual and political movements, but evolutionary. It is not against traditions, but rather appreciates their value and tries to build on them. It does not want to undermine religions, but rather seeks to uncover what is truly valuable in them-their spirituality. Particularly, it revitalizes the tradition of classical rationality. "In classical rationality, reasoning is not only an instrument to achieve various benefits, but primarily an axiological reflection on what is morally good or bad, favorable or unfavorable, right or wrong" (9.212). Classical rationality, which at its core is an evolutionary one, involves thinking and speaking meaningfully about values. It is expressed in politics "in the pragmatism of actions aimed at a good life" (9.216). A good life is not only "the wealth or material prosperity of human beings, but also their spiritual (moral and intellectual) development" (1.21). It leads to their happiness or selfrealization [4].

Korab-Karpowicz invites us to think of tradition, modern and postmodern as epochs. He invites us to realize how our present moment is characterized by the clash of epochs, namely clashes among the epochs of tradition, modern and postmodern. The epochs of tradition and modernity are not totally compatible with one another and there are conflicts between them, for example, conflict between the emphasis on community in tradition and the emphasis on individualism in modernity. Similarly, there are conflicts between epochs of modernity and postmodernity around issues of reason and limits to reason. Yet, there are not only clashes among epochs but also clashes within resonating with issues such as inner conflicts of both tradition and modernity [5, 6]. Further there are not only clashes among epochs, there are also dialogues among epochs as there is not only clash of civilizations there are also dialogues among civilizations [7, 8]. There are both clashes and conciliations within and across epochs and civilizations leading to such formations as modernity of tradition and traditional roots of the postmodern $[9,10]$.

Evolutionity, the future evolutionary age, like tradition, modernity and postmodernity is not just a fixed entity but a dynamic process. It is not a noun but a verb--a manifold verb of action, meditation and co-realization of self, society, Nature, Divine and the world. We can realize evolutionity as a meditative verb of co-realization of self, society, Nature, Divine and the world [11]. In his work, Korab-Karpowicz engages us with tradition, modernity and postmodernity, as well as with the future. We can also invite the perspective of transmodernity to this exploration. In transmodernity, as Enrique Dussel, the deep philosopher from Latin America tells, we build on tradition, modernity and postmodernity but we also strive to overcome their limitations and create movements for renewal and reconstructions from their bases and horizons [12]. We believe that Prof. Korab-Karpowicz's reflections on the contemporary epoch and the conjoint perspective on evolutionity can be enriched by integrating this perspective of transmodernity to evolutionity.

\section{Dialogues Among Epochs}

Different epochs are not just different from each other. They also share some common concerns such as valuing life in their own ways. There is much to learn from each other 
such as tradition learning from modernity and postmodernity learning from both tradition and modernity. For this dialogue to happen we need critique as well as appreciation of limits and possibilities of each of these epochs. We also need to overcome a developmentalist approach to epochs which assumes that succeeding epochs are better than the prior ones. In such approaches, one becomes a prisoner of arrogant presentism which hinders learning and dialogues across epochs. To realize the manifold realities and possibilities of epochs, we need to develop a new time consciousness and relationship with time, a new temporality. This temporality is also a pregnant temporality which has the capacity to empty itself from its presuppositions and engage with the transformative possibilities in other epochs. Such a pregnant temporality can create new realities, relationships and possibilities.

\subsection{Multi-topial and Multi-temporal Hermeneutics}

For dialogue among epochs, we need to move across epochs. We can realize epochs as multi-dimensional spatial and temporal formations animated by the dialectics of values and power and for dialogue among epochs we need to move across different spatial and temporal formations of epochs as well as move across different fields of dialectics of values and power characterizing, constituting and shaping these epochs [13]. While moving across different spatial and temporal formations of epochs, we can build upon the pathways of diatopical and multi-topial hermeneutics cultivated by Raimundo Panikkar, Boaventuara de Sousa Santos and others $[14,15]$ which helps us go beyond fixed positions of self, culture, space and society and put our feet in two cultures [16]. In multi-topial hermeneutics we put our feet in multiple topoi and terrains of self, culture, realities and aspirations of our world [17].

By taking this multi-topial hermeneutics into our movement across epochs and temporalities we can cultivate multi-temporal hermeneutics which helps us go beyond taken for granted fixed assumptions and determinations of epochs and realize fluid border-crossing among them. This presents us a new hermeneutics of self, culture, society and the world, which is other than the conventional narratives presented to us such as that of conflicts between tradition and modernity which does not help us realize modernity, postmodernity and transmodernity of traditions. Multi-topial and multi-temporal hermeneutics is animated by a multi-valued logic where different epochs and positions are not just opposed to each other in an either-or mode but they represent different dimensions of our inter-connected existence [18]. For this we need a new ethical awakening such as discourse ethics as nurtured by Jurgen Habermas where we go beyond our existing models of self-justification as well as justification of others and engage with each other in a spirit of critical, transformative dialogues and learning $[19,20]$. We also need to cultivate a new aesthetics of discovering threads of connections across different cultures and epochs [21, 22]. Dialogue among epochs and the accompanying multitemporal and multi-topial hermeneutics call for creative, critical and alternative memory works where we realize memories of epochs in new ways going beyond their given definitions and presentations.

\subsection{New Realizations of Power, Sraddha and Dialectics}

In his article "The clash of epochs: traditional, modern, postmodern, and evolutionity", as well as in his oryginal philosophical work, Tractatus Philosophicus Politicus, Korab-Karpowicz invites and challenges us to understand the limits of power and power model as he writes: "Power is not the proper goal. The true end is not for any particular nation, religion, ideology, or political or economic system to overcome all the rest and affirm its unchallenged world domination. We have a higher task to be completed. We are vehicles of further evolution" [23]. Understanding the limits of power is particularly essential for cultivation of evolutionity since most of the existing regimes of power want to preserve the status quo and use power to nip in the bud evolutionary potential in self, society, culture and the world. We need a different cultivation of power for evolution, a shift from power over to power with which can give birth to new self, culture, society and the world. This is cultivated by Benedict Spinoza, Mohandas Karamchand Gandhi and Hannah Arendt, among others, where to have power is to act in concert with each other [24]. This itself is a process of new value formation where we transform our addiction to power as domination to power as co-creation. At the same time, we need to understand self, society, culture and evolution as working with and emerging out of the dialectic of value and power. We need to pay attention to how both of these influence shape, determine and transcend each other [25].

We also need a new realization of dialectics where dialectics primarily refers to processes of self and social transformations and realization of an open totality in an evolutionary way rather than attainment, production and reproduction of closed totalities [26, 27]. We also need to realize the political, moral and spiritual struggles involved in this dialectic of value and power leading to emergence of alternative conceptualization and realization of both values and power where means to act and meditate in cooperation with each other and values mean cultivating ways of thinking and envisioning which contributes to flourishing of life. Another variant of this is to realize the dialectic of value and sraddha which means love and respect which urges to realize that we are not only beings of power but of sraddha. We need to embody evolutionary configurations of power and sraddha. Sraddha has the power to counter and reconstitute structures of power which disrespects which leads to annihilation and death of self, society and the world [28, 29]. For evolutionary unfoldment, we need to embody new visions and practices of sraddha as well as a new dialectics of power and sraddha which can help us transcend one-sided valorization of either power or sraddha. It can also help us overcome limits of pervasive ideological conflicts and also ideological enslavement which mars our ability to communicate and learn with each other across constructed and supposed divides in creative and open ways. It can help 
us embody ideal life in our everyday lives and institutional settings and embody idealization in creative and transformative ways, an effort which also embodies a new dialectics of values and power, power and sraddha [30, 31]. A new dialectic of idealization of power helps us overcome the trappings of the epochs and realize evolutionary potential that is latent in our conditions of self, culture, society, epochs and the world.

\section{Evolutionity and the Calling of Evolutionary Learning}

Evolution happens in human society in complex, nonlinear ways. Despite failures of history such as wars and genocide such as Auschwitz, we have created some institutions and frameworks of thinking so that we strive our best not to perpetrate these mistakes and embody and nurture learning - evolutionary learning [32]. To take part in our current condition of evolutionity we need to think and work further on visions and practices of evolutionary learning. Such an evolutionary learning acknowledges failures of traditions, modernity as well as postmodernity as well as tries its best learn from their failures as well as their potentials. This embodies love and labor in the midst of propensity to quick judgment of categorical hatred and laziness of thinking and being. The challenge before us is how do we work and meditate with existing self and social institutions as passages and movements of evolutionary learning which also involves a complex acknowledgement of relationship between contingency and transcendence. Evolutionary learning involves creative acknowledgement of contingencies, emergence (emergence of new ideas and relationships) as well as transcendence. It involves not only the double contingency learning of self and other, or self versus the other but the triple contingency learning of self, other and the world. It also involves not only double transcendence learning of self and the other, or self versus the other but also the triple transcendence learning of self, other and the world [33]. Evolutionary learning is also integral learning which is different from fragmentary learning. For cultivation of evolutionity, we need to cultivate new visions and practices of integral learning which also involves learning new ways of how to learn as well as unlearn [34].

\subsection{Evolutionary Learning and Ontological Epistemology of Participation}

For evolutionary learning we need new visions and practices of knowing and being--epistemology and ontology. As Korab-Karpowicz writes: "I assume that reality is in a process of evolution and unfolds to us as we are ourselves engaged in a self-transforming process. In order to grasp the evolving reality, which is continually unfolding to us, our thinking itself must be evolutionary" [35]. For this we also need transformations of our visions and practices of both epistemology and ontology. Modernity gives primacy to the epistemic and does not pay sufficient attention to cultivating the ontological as a field of self-realization and selftransformations. We need to overcome the dualism between epistemology and ontology and embody what can be called ontological epistemology of participation [36]. It also involves what Michael Foucault [37] calls an ontology of the present and Vattimo [38] an ontology of actuality where we understand the multiple dimensions of the present as pluriversal reality and possibility going beyond determinism and fatalism of epochs and past, present and future [39].

\subsection{Evolution and Involution}

As Korab-Karpowicz describes it: "Evolution can be defined as the process by which reality, or what exists, emerges in stages in which novelty, variety, and sophistication are generated" [40]. Evolution is truly a multidimensional process-biological, cultural, social and spiritual. It works in the complex fields of Nature, Human and Divine. According to Sri Aurobindo, evolution involves involution. What is to evolve is already present in us as involution and we have to unfold it with sraddha, creative potency, sadhana and struggles. In his magnum opus, Life Divine Sri Aurobindo tells us: "Life is already in Matter and Mind in Life because in essence Matter is a form of veiled Life, Life a form of veiled consciousness" [41].

Sri Aurobindo here suggests a principle of evolution and involution, ascent and descent. For Sri Aurobindo, “Ascent or Evolution is only possible because there has been Descent or Involution. Matter can evolve because there has been a descent of spirit into matter. As with Matter, so also with Life, Soul and Mind. Each of these can evolve, because there has been an involution of spirit into it" [42].

Furthermore, "evolution is not merely an ascent from a lower to a higher state of being, it is also an integration of the higher with the lower status. This means that when a higher principle emerges, it descends into lower ones and causes a transformation of them" [42]. For example, in the evolutionary journey when mind emerges "not only does a new principle appear on the scene, but the lower principles of matter and life also undergo a transformation so that they become different from what they were before the emergence of mind" (ibid). Sri Aurobindo thus urges us to understand the need for integrating the vertical with the horizontal in our evolutionary striving and discourse of evolution. The higher is consciousness and self-realization, there is a need to come down to the lower - the noble need to come down to the lower strata of society and engage in sadhana and struggles to uplift them. Korab-Karpowicz speaks about the significance of nobility in society and history [43], and he can now link this to a journey of responsible descent and ascent in consciousness work and social engagement. The vision and practice of evolution needs also to realize the dimension of involution, and work and meditate for its realization and evolutionary manifestation. In this work and meditation, consciousness which is simultaneously social and transcendental plays an important role.

Another important dimension of evolution in Sri Aurobindo is psychicization, "that is to say, the opening out 
of the psychic being within. Evolution is not only a movements upwards and a movement downwards, but is also a movement inwards. [..] within us dwells a spark of divinity [..] Evolution means the development of this psychic being [..] [44]." A very different evolutionary possibility "opens if we can live within the inner being [44]." This resonates with Korab-Karpowicz's emphasis on inner development of self and society and its moral and spiritual development.

\subsection{Intuition and Evolutionary Unfoldment}

Korab-Karpowicz invites us to understand the significance of intuition in evolutionary unfoldment: "Intuition can give us a vision" [45]. This resonates with the perspectives of both Henri Bergson and Sri Aurobindo on evolution. Bergson helps us to understand that further development of intuition in the context of the overwhelming static presence of intellect is an evolutionary challenge. For Bergson, "[..] intellect does not admit of the unforeseeable"; it is "skillful in dealing with the inert" and "awkward the moment it touches the living [46]." In his understanding, "[..] intuition is mind itself, and, in a certain sense, life itself [..]. Thus is revealed the unity of spiritual life. We recognize it only when we place ourselves in intuition in order to go from intuition to intellect [..] [46]." Sri Aurobindo also invites us to cultivate living spiritual intuition which can guide us in our evolutionary journey. Building upon both Bergson and Sri Aurobindo as well as Edmund Husserl [47] who also invites us to realize the work of living intuition in our phenomenological journey, we need to cultivate cultures of intuition which would help us in our evolutionary learning and journey.

\subsection{Happiness, Transformative Harmony and Ananda}

One goal of evolution is to realize happiness as KorabKarpowicz speaks about this in his Tractatus Philosophicus Politicus. But we can realize happiness as well-being of self, other and the world which constitutes Ananda-joy or bliss. Happiness has both material and spiritual dimension. Agricultural scientist M. S. Swaminathan speaks about biohappiness which is nurtured by both cultural and biological diversity and Korab-Karpowicz can engage with this perspective of biohappiness for a fuller realization of his vision of happiness [48].

Korab-Karpowicz lays emphasis on co-operation as a goal for evolutionary development as well as a means. Here we can build upon works such as Peter Kropotkin's Mutual Aid who invites us to realize co-operation as a factor in evolution [49]. We can consciously cultivate visions and circles of co-operative thinking and action which would help us in our journey with evolutionity at present. In this we can build upon creative memory work of practices of co-operation-past and present-- in societies and cultures around the world such indigenous cultures of the world where co-operation such as co-operative labor plays an important role [50]. But co-operation is not always devoid of conflict and we need to acknowledge existing conflicts in self and society including inner conflicts and work towards creating circles of co-operative conflicts which would help us in our evolutionary journey [51]. Korab-Karpowicz tells us about the significance harmony in our self and society and the need for creating a harmonious society, state and the world. But this harmony is not static but dynamic. It is also not an apology for continuing existing structures of domination and disrespect in society in the name of harmony. Harmony which helps us in our evolutionary journey is transformative which involves co-operation as well as conflict, confrontation as well as compassion [52]. Just talking about harmony and harmonious society is not enough unless we realize this as transformative harmony. Korab-Karpowicz can integrate the vision and practice of transformative harmony to his discourses of evolutionity and harmony.

Korab-Karpowicz also here can undertake a much needed transcultural journey in deepening and widening his vision and practice of harmony by engaging with the vision of harmony in Indic concept of lokasamgraha and the vision of Tian-Xia in Chinese culture. For example, Lokasamgraha is spoken about in Bhagavad Gita which challenges us to realize gathering of people and this gathering is not only a public gathering but also a soulful gathering. This helps us realize happiness and harmony. In modern social and political thought and practice, we are used to the vision and practice of public sphere and we can realize and transform this also as a field and practice of lokasagrahma which is simultaneously public and soulful leading to realization of a deeper harmony. Lokasamgraha is a field of mutual care and responsibility and it is a challenge at all levels of human gathering-from dyadic associations, institutions and movements to the triadic and beyond such as family, community, nation and the global order. In our present phase of globalization and the challenges of global responsibility via such challenges as climate change and terrorism, we need to talk about and cultivate a planetary lokasamgraha [53]. This planetary lokasamgraha becomes a field of a new cosmopolitan realization where to be cosmopolitan is not only to be a citizen of the world but also to be a member of the human family [54]. It is also not only epistemological and political but also ontological and spiritual. Lokasamgraha here can be thought and realized together with the vision and practice of Tian-Xia-all under Heaven. We are all interwoven all under Heaven and despite the hierarchical manifestations of this in Chinese traditions and histories, Tian Xia now needs to be realized as a place of lokasamgraha where we are all equal and are challenged to lead a rightful life [55].

\section{Evolutionary Suffering and Evolutionary Flourishing: Cultivating New Pathways of Planetary Realizations}

Evolutionity is not static and despite its comprehension as a noun in English language we can realize it as a verb but as 
a verb it is not just activistic, it is also meditative. Evolutionity embodies meditative verbs of co-realizations in which Divine, Nature, self, culture and society are entangled in manifold ways and webs of challenges and responses. It also involves conflicts as well as co-operation, compassion and confrontation, agony as well as agape. Evolutionity as a meditative verb of co-realization leads to flourishing which is not reproduction of existing structures and consciousness. Evolution involves questioning, interrogation, abandonment of those aspects of our structures and consciousness which hinder our evolutionary potential and this requires courage and creativity. This involves pain and suffering for those who take the cross of such questioning and transformations. Evolutionity calls for self and institutions to prepare themselves for such evolutionary suffering. Evolutionary suffering also refers to the pain of giving birth to a new evolution, for example, the needed transition from a world full of violence to a world and consciousness characterized by ahimsa-active non-violence or least possible violence. We also need to cultivate evolutionity as evolutionary flourishing where we are engaged in both sadhana and struggles for transformation of existing structures, institutions and consciousness. Evolutionary flourishing is a destination, a path as well as a method which involves creative engagement with technology, institutions, movements - social as well as consciousness movementsand self. It involves ethics, aesthetics as well as responsibility.

Evolutionary flourishing involves dialogues among epochs and not only clashes among them. Evolutionary flourishing helps us realize that we are part of our planet--our Mother Earth-- as well as we are part of our nurturing Cosmos. This is the other name of planetary realization which challenges us go beyond the limits of nation-state centered rationality as well as anthropocentrism and invite us to work for and meditate with evolutionary flourishing and reduction and transformation of suffering of all beings and not just of the humankind. We need to cultivate new pathways of planetary realization which involves dialogues, walks and works across epochs, cultures, civilizations, species as well as a realization that we are not just beings of power and consumption but beings of evolutionary transformation of self, society, world and cosmos.

\section{Evolutionity and the Calling of Dialogues Among Epochs and Evolutionary Flourishing: In Lieu of a Conclusion}

In his recent works on evolution, philosophy, politics and morality, Korab-Karpowicz has made important contributions to our thinking about our contemporary human condition. But some of these ideas can be deepened and broadened by bringing cross-cultural and trans-cultural dimensions to this as suggested in this essay. We can engage ourselves with the dialogues among epochs and realize multiple realities and possibilities in tradition, modernity, postmodernity and transmodernity. We can simultaneously work on reason and intuition for realization of creative evolutionary potential of self and society. We can cultivate new visions and practices of evolutionary learning and undertake evolutionary suffering for evolutionary flourishing.

\section{Acknowledgements \& Gratitude}

I finalized the draft of this essay during my stay at the Jai Jagat Center, Pondicherry, India in the first week of April 2021 and I wish to thank friends of the Center especially Mr. PV Rajagopal and Mr. Ajit Rajagopal for their kind hospitality and interest. I thank Vishnu-Mr. Vishnu Varatharajan of Graduate Institute, Geneva - and Swathi for their kind help.

\section{References}

[1] W. Julian Korab-Karpowicz, (2017). Tractatus PoliticoPhilosophicus: New Directions for the Future Development of Humankind. London: Routledge.

[2] Gianluca Bocchi \& Mauro Ceruti. (2002). The Narrative Universe. Translated by Luca Pellegrini \& Alfonso Montour. Cresskill, NJ: Hampton Press, pp. 159-160.

[3] Arnold J. Toynbee. (1956.) An Historian's Approach to Religion. Oxford: Oxford U. Press, p. 74.

[4] W. Julian Korab-Karpowicz. (2019). The Clash of Epochs: Traditional, Modern, Postmodern, and Evolutionity. Perspectives on Political Science 48 (3): 170-182.

[5] Prasenjit Duara (2015) The Crises of Global Modernity: Asian Traditions and Sustainable Futures. Cambridge: Cambridge University Press.

[6] J. C. Heesterman (1985), The Inner Conflicts of Tradition: Essays on Indian Ritual, Kingship and Society. Chicago: University of Chicago Press.

[7] Dallmayr, Fred. (2002). Dialogue Among Civilizations: Some Exemplary Voices. New York: Palgrave Macmillan.

[8] Richard Hartz. (2015). The Clasp of Civilizations: Religion and Globalization in a Multicultural World. New Delhi: D. K. Printworld.

[9] Harvey, David. (1989.) The Condition of Postmodernity: An Inquiry into Origins of Cultural Change. Boston: Basil Blackwell.

[10] Rudolph, Lloyd and Susanne H. Rudolph. (1967.) The Modernity of Tradition: Political Development in India. Chicago: University of Chicago Press.

[11] Ananta Kumar Giri. (2013). Knowledge and Human Liberation: Towards Planetary Realizations. London, Anthem Press.

[12] Dussel, Enrique. (2017). "Transmodernity and Interculturality: An Interpretation from the Perspective of Philosophy of Liberation." In Research as Realization: Science, Spirituality and Harmony. Delhi: Primus Books. 
[13] In making such a formulation of the dialectic between values and power in understanding epochs and civilizations, I draw upon sociologist Andre Beteille's work on ideology which looks at it as the dialectic between power and symbols. See Andre Beteille, Ideologies and Intellectuals. Delhi: Oxford U. Press, 1980

[14] Boaventuar de Sousa Santos. (2014). Epistemologies of the South: Struggles Against Epistemicide. Boulder, CO: Paradigm Publishers.

[15] Ananta Kumar Giri. (2021). "With and Beyond Epistemologies from the South: Multi-topial Hermeneutics, Ontological Epistemology of Participation and Planetary Realizations.” Sociological Bulletin, 70 (3), pp. 366-383.

[16] Baventuar de Sousa Santos writes about this: The aim of diatopical hermeneutics is to maximize the awareness of the reciprocal incompleteness of cultures by engaging in a dialogue, as it were, with one foot in one culture and the other in another-hence its diatopical character. Diatopical hermeneutics is an exercise in reciprocity among cultures that consists in transforming the premises of argumentation in a given culture into intelligible and credible arguments in another. See Boaventuar de Sousa Santos. Epistemologies of the South, op. cit., p. 92.

[17] Ananta Kumar Giri (2021), "Cultural Understanding: Multitopial Hermenuetics, Planetary Conversations and Dialogue with Confucianism and Vedanta." International Journal of Communication of Chinese Culture, 2020.

[18] What philosopher J. N. Mohanty writes deserves our careful consideration: The ethic of non-injury applied to philosophical thinking requires that one does not reject outright the other point of view without first recognizing the element of truth in it; it is based on the belief that every point of view is partly true, partly false, and partly undecidable. A simple two-valued logic requiring that a proposition must either be true or false is thereby rejected, and what the Jaina philosopher proposes is a multi-valued logic. To this multi-valued logic, I add the Husserlian idea of overlapping contents. The different perspectives on a thing are not mutually exclusive, but share some contents with each other. The different 'worlds' have shared contents, contrary to the total relativism. If you represent them by circles, they are intersecting circles, not incommensurable, [and it is this model of] intersecting circles which can get us out of relativism on the one hand and absolutism on the other. In this spirit, we can realize that different epochs have "shared contents" among each other which facilitate dialogues among epochs. See, J. N. Mohanty (2000), Self and Other: Philosophical Essays. Delhi: Oxford U. Press, p: 24; emphases added.

[19] Jurgen Habermas. (1990). Moral Consciousness and Communicative Action. Cambridge, MA: The MIT Press.

[20] Ananta Kumar Giri (2012), "Beyond Adaptation and Meditative Verbs of Co-Realizations," [in:] Sociology and Beyond: Windows and Horizons. Jaipur: Rawat Publications.

[21] Ankersmit, F. R. (1996). Aesthetic Politics: Political Philosophy Beyond Fact and Value. Stanford: Stanford U. Press.

[22] Clammer, John; Ananta Kumar Giri. Eds. (2017). The Aesthetics of Development: Art, Culture and Social Transformation. New York: Palgrave Macmillan.

[23] Korab-Karpowicz, Tractatus Politico-Philosophicus, p. 4.

[24] Here what Chitta Ranjan Das writes about Benedict Spinoza:
Power, knowledge and the challenge of cultivation of higher consciousness deserves our careful consideration: Benedict Spinoza has spoken about potestas and potential-words that in Latin mean power. They are different in their import because they point to different connotations. The former is functionally the urge to possess by bossing it over others, and the latter reminds us about the potentials inherent in every human being, the many possibilities of flowering up and upholding, if freedom is the climate in which it develops. According to Spinoza, love is the mediating link between knowledge and power. Love of humanity, love of the world, a deep faith in the unending possibilities of individuals as well as the collectives. This calls for a higher consciousness that all knowledge should congenially aim at. To Sri Aurobindo, a higher consciousness, as a rule, has to prove itself in the world. It never runs away and can afford to prove itself to be an asset of the world. But the changeover is not that easy as the wonderful words and references may suggest. There will be many-a-restraint, obstacles and oppositions, both from without and within. Hence, those who have chosen love have been men of protest. See Chitta Ranjan Das (2009), "Afterword," The Modern Prince and the Modern Sage: Transforming Power and Freedom, ed. Ananta Kumar Giri. Delhi: Sage.

[25] Sociologist Andre Beteille looks at ideology as a dialectic of value and power. But Beteille does not explore much transcendence and transformation of our existing conceptions, organization and configurations of values and power. See Andre Beteille (1980), Ideologies and Intellectuals, Delhi: Oxford University Press.

[26] Roy Bhaskar (1996) Dialectics: Pulse of Freedom. London: Verso, 1996.

[27] Ananta Kumar Giri. (2001) ed. Rethinking Social Transformations: Criticism and Creativity at the Turn of the Millennium. Jaipur: Rawat Publications.

[28] Ananta Kumar Giri. 2018. (ed.) Beyond Sociology: Transcivlizational Dialogues and Planetary Conversations. New York: Palgrave Macmillan.

[29] Axel Honneth, (2007) Disrespect: Normative Foundations of Critical Theory. Cambridge: Polity Press.

[30] The Indian transformative thinker Chitta Ranjan Das speaks about cultivating ideal lives in our daily lives which is different from clinging to particular ideologies and phenomenologist Edmund Husserl talks about idealization which involves a different mode of perception where we perceive the far to be near. See Ananta Kumar Giri and Ivan Marquez (2002), eds, The Essays of Chitta Ranjan Das on Literature, Culture and Society: On the Side of Life in Spite of. New Castle Upon Tyne: Cambridge Scholars Press.

[31] J. N. Mohanty (2002), Self and Other: Philosophical Essays. Delhi: Oxford U. Press.

[32] See Jurgen Habermas. (1979). Communication and the Evolution of Society. Boston: Beacon Press.

[33] Piet Strydom. (1989). New Horizons of Critical Theory: Collective Learning and Triple Contingency. Delhi: Shipra.

[34] Ivan Ilich. (1972). Deschooling Society. New York: Harper \& Row.

[35] Korab-Karpowicz, Tractatus Politico-Philosophicus, p. 19.

[36] Ananta Kumar Giri (2017), ed. Pathways of Creative Research: Towards a Festival of Dialogues. Delhi: Primus Books. 
[37] Michel Foucault (1984). "What is Enlightenment?" In Foucault Reader, Ed. Paul Rabinow. New York: Pantheon.

[38] Giani Vattimo (2011) A Farewell to Truth. New York: Columbia University Press.

[39] Arturo Escobar. (2021). Pluriversal Politics. Durham: Duke University Press.

[40] Korab-Karpowicz. The Clash of Epochs, p. 8.

[41] Sri Aurobindo (1970). Life Divine. Pondicherry: Sri Aurobindo Ashram, p. 3.

[42] This passage us quoted in S. Maitra, (2000), The Meeting of the East and West in Sri Aurobindo's Philosophy. Pondicherry: Sri Aurobindo Ashram.

[43] It is especially visible in the part of the Tractatus entitled Sophocracy, which is a name for an ennobled democracy. See Korab-Karpowicz, Tractatus Politico-Philosophicus, pp. 89102.

[44] S. Maitra, (2000), The Meeting of the East and West, p. 71.

[45] Korab-Karpowicz, Tractatus Politico-Philosophicus, p. 21.

[46] Henri Bergson, Henri, Creative Evolution. Tr. Arthur Mitchell. London: Macmillan, 1912.

[47] J. N. Mohanty. 2002. Explorations in Philosophy: Western Philosophy. Delhi: Oxford U. Press.

[48] What Swaminathan writes here deserves our careful consideration: How can we define biohappiness? I woud say it is the sustainable and equitable use of biodiversity leading to the creation of more jobs and income. When the use of biodiversity leads to sustainable livelihood security, the local population develops an economic stake in conservation. It means that growth and progress must be reliable and dependable and maintained at an even and steady pace. In farming it is the production of high yields in perpetuity, without associated social and ecological harm. Sustainable development must be firmly rooted in the principles of ecology, social and gender equity, employment generation, and economic advance. See M. S. Swaminathan, In Search of Biohappiness: Biodiveresity and Food, Health and Livelihood. Singapore: World Scientitic, 2011, p. ix.

[49] Peter Kropotkin. (1976). Mutual Aid: A Factor in Evolution. Boston: Porter Sergent Edition.

[50] Bikram Narayan Nanda. (1994). Contours of Continuity and Change: The Story of the Bonda Highlanders. Delhi: Sage.

[51] See Amartya. Sen (1987), Gender and Cooperative Conflicts. Helsinki: World Institute of Development Economics (WIDER) Working Paper.
[52] Ananta Kumar Giri, ed. (2019). Transformative Harmony. New Delhi: Studera.

[53] Ananta Kumar Giri. (2020). "Upholding Our World and Regenerating Our Earth: Planetary Lokasamgraha." In Cosmopolitan Civility: Global-Local Relations with Fred Dallmary, ed. Ruth Abbey. Stonybrook: State University of New York Press.

[54] Ananta Kumar Giri. Ed. 2018. Cosmopolitanism and Beyond: Towards Planetary Transformations. New York: Pagrave Macmillan, 2018.

[55] Here what Fred Dallmayr writes deserves our careful consideration: As an antidote to the spread of "worldlessness" in our time, Hannah Arendt recommended the restoration of a "public realm" in which people would actively participate and be mutually connected. Digging beneath this public forum, Heidegger unearthed the deeper source of connectedness in the experience of "care" (Sorge, c ura) in its different dimensions. From the angle of human "being-in-the world," care penetrates into all dimensions of this correlation - in the sense that existence is called upon to care about "world" and its constituent features (fellow-beings, nature, cosmos). Differently put: There cannot be, for Heidegger, an isolated "self-care" (c ura sui) without care for the world-that includes care for world maintenance (without which Dasein cannot exist). In this latter concern, is work does not stand alone. In the Indian tradition, especially the Bhagavad Gita, we find an emphasis on a basic ethical and ontological obligation: the caring attention to "world maintenance" or loka-samgraha. According to the Gita, such attention needs to be cultivated, nurtured and practiced in order for human life to be sustainable and meaningful. See, Fred Dallmayr. (2015), Against the Apocalypse: Recovering Humanity's Wholeness. Lanham, MD: Lexington Books, pp. 51-52.

\section{Biography}

Ananta Kumar Giri is a Professor at the Madras Institute of Development Studies, Chennai, India. He has taught and done research in many universities in India and abroad, including Aalborg University (Denmark), Maison des sciences de l'homme, Paris (France), the University of Kentucky (USA), University of Freiburg and Humboldt University (Germany), Jagiellonian University (Poland) and Jawaharlal Nehru University, New Delhi. $\mathrm{He}$ has an abiding interest in social movements and cultural change, criticism, creativity and contemporary dialectics of transformation, theories of self, culture and society, and creative streams in education, philosophy and literature. Dr. Giri has written and edited around two dozen books in Odia and English. 